\title{
Study on the mechanical properties of unsaturated polyester sandwich biocomposites composed of uniaxial warp-knitted and non-woven viscose fabrics
}

\author{
Mikael Skrifvars ${ }^{1}$, Hom Dhakal*2, Zhongyi Zhang ${ }^{2}$, Joseph Gentilcore², \\ Dan Åkesson ${ }^{1}$ \\ ${ }^{1}$ Swedish Centre for Resource Recovery, University of Borås, S-510 90 Borås, \\ Sweden. \\ ${ }^{2}$ Advanced Materials and Manufacturing (AMM) Research Group, School of \\ Mechanical and Design Engineering, University of Portsmouth, Portsmouth, \\ Hampshire, POI 3DJ, U.K.
}

\begin{abstract}
In this work, tensile, flexural and the low-velocity impact response of regenerated biodegradable warp-knitted and non-woven viscose fabric reinforced unsaturated polyester (UP) sandwich biocomposites are reported. Four different types of sandwich laminates comprised of different configurations as well as various weight fractions of warp knitted/non-woven fabrics were manufactured by vacuum infusion moulding (VI). The influence of warp knitted/non-woven ratios in the sandwich surface layers and core layer and lay-up configurations on the tensile, flexural and low velocity impact damage characteristics have been investigated. It was observed from the experimental results that fibre lay-up configurations have a considerable effect on the mechanical properties of regenerated cellulose reinforced sandwich biocomposites. The tensile strength was increased from 50 MPa for sandwich laminate SL1 (22 wt-\% of reinforcement) to 160 MPa for sandwich laminate SL4 (39.8 wt-\% of reinforcement). Similar trend was observed for impact behaviour, showing the best penetration resistance by SLA laminate.
\end{abstract}

Keywords: A. Regenerated cellulose; A. Biocomposites; B. Impact behaviour; C. Damage mechanics; D. Mechanical testing.

\footnotetext{
* Corresponding author. Tel: + 44 (0) 239284 2582; fax: + 44 (0) 2392842351.

E-mail: hom.dhakal@port.ac.uk
} 


\section{Introduction}

In recent years, there is an increased interest in the use of sustainable biocomposites due to the environmental burden created with the use of non-renewable carbon or glass fibre composites [1,2]. Extensive research works have been conducted in the past focusing on the development and testing of composites using natural fibres and thermoset and thermoplastic polymer matrices [3-6]. These natural fibre reinforced composites are becoming more popular due to their environmentally friendly, acceptable specific properties, and biodegradable attributes. Natural fibres have shown their potential, and can be good replacements for glass fibres in composite applications as these are natural, renewable and abundant [7-9].

In the automotive sector, natural fibre composites are particularly interesting due to their much lower specific weight compared to glass fibres. This is enhanced by the European Directive (2000/53/EC) on the disposal of vehicles states that by $1^{\text {st }}$ January 2015 vehicles should be by weight at least $85 \%$ reusable, $10 \%$ by weight recyclable, and only 5\% may go to landfill [10]. Natural fibre composites are most commonly used in interior applications (inside door panels, dashboard and trim) but there is also a need to develop stronger biocomposites for exterior panels where impact strength is especially required $[11,12]$.

Despite their many attractive attributes such as high specific strength and modulus, biodegradability compared to conventional fibre reinforced composites, natural fibre composites are susceptible to internal damages caused by low-velocity impact (LVI) loading. LVI damage for example analogous to several real life situations, such as damage during manufacture, feasibly due to human error such as dropping tools and mishandling of the finished products and a vessel collision with another. As a result of such damages, the structural integrity of composites significantly reduces. For example, the work carried out by Sy et al. [13] on unidirectional and cross-ply flax/epoxy laminates subjected to LVI loading suggested that the unidirectional laminate exhibited poor and brittle failure behaviour compared to cross-ply laminates. Similarly, the ageing behaviour of jute and interplay jute/basalt hybrid laminates exposed to salt-fog and evaluated under quasi-static three-point bending and LVI testing. Their results highlighted that the salt-fog exposure influenced the microstructural integrity of the laminates causing severe damage to fibre matrix interfaces for both jute and jute/basalt hybrid systems [14]. Therefore, amongst other properties, understanding of LVI 
damage mechanisms is important for these composites to be used in various engineering applications $[15,16]$.

Viscose or rayon, is a man-made fibre prepared by regeneration of dissolved cellulose, which has been used since late $19^{\text {th }}$ century as a textile yarn. In technical applications for example, at present, viscose yarns are used as tire cord to reinforce car tires. Compared to plant origin natural fibres such as hemp, jute and flax, viscose fibres are produced in an industrial process to continuous filaments, and they can be easily converted to similar reinforcement fabrics as glass fibres, but with much lower weight. Their high tenacity and low density can provide high specific strength and good impact resistance $[17,18]$. Due to the ductile characteristics of viscose, it is also expected that these fibres could be used in composites where toughness properties cannot be compromised.

The possibility of using viscose as a reinforcement in both thermoplastic and thermoset composites have been reported by several researchers. In thermoplastic composites, the use of viscose as a reinforcement has been reported for high-density polyethylene [19], polypropylene [20-23], polylactic acid [24,25], polyhydroxybuturate [26] and polyamide-6 [26]. In these studies, both short and long viscose fibres have been used. These researchers have pointed out that the fibre-matrix compatibility has been improved by surface treatments, which is normally needed when combining a polar fibre like viscose with a non-polar polymer. The favourable composite impact properties have particularly been reported in these studies [20, 24, 26, 27]. Thermoset composites reinforced with viscose have been produced by hand lay-up method using needle punched non-woven viscose fabrics and epoxy resins [28] and from carded nonwoven viscose fabrics and soy bean oil [29]. Besides several advantages, the thermoset composites for example, exhibit brittle failure fracture behaviour and poor crack propagation, lacking good toughness behaviour and limiting to be used in structural applications [30].

Natural fibre composites and biocomposites can potentially replace the traditional synthetic composites as an alternative for lightweight applications [31-33]. The acceptance of biocomposites (partially or fully biodegradable) in critical applications such as automotive, marine and construction is dependent on their mechanical properties (strength, stiffens and toughness), thermal stability and durability during their service life [34]. Moreover, understanding their failure mechanisms is equally 
critical in order for these biocomposites to be used in structural and semi-structural applications $[35,36]$.

The main objective of the present work is to investigate the possibilities to optimise and tailor the properties and performance of viscose fibre reinforced composites by constructing sandwich type configuration. A sandwich composite is particularly useful in applications where superior flexural bending strength is required, such as floor and wall panels, doors and other structural elements. A good impact strength is also required in these applications, especially when used in transport applications. By using two different types of viscose fabrics, sandwich type laminates can be made, and this combination could have a potential use in automotive and transport applications.

Therefore, in this study, sandwich composites were fabricated by incorporating specific configuration of a uniaxial non-crimp fabric in the surface layers of the sandwich and a non-woven fabric as the core layer. The resin was an unsaturated polyester, with a biobased content of $13 \mathrm{wt}-\%$. The sandwich composites with different ratios of uniaxial and non-woven fabrics were fabricated by vacuum infusion method. The tensile, flexural and impact properties of obtained composites were investigated with a view to develop a low cost sandwich laminates for structural composite applications.

\section{Experimental details}

\subsection{Materials}

Four sandwich composite lay ups with different composition of uniaxial fabric as surface layers and non-woven fabric as core layers were used. The composites were fabricated by vacuum infusion method using an unsaturated polyester resin (UPR), Envirez G8600 INF-60, supplied by Ashland, Finland. The resin has a biobased content of $13 \mathrm{wt}-\%$, which is originated from soy bean oil derivatives. The biobased content for the resultant composite will therefore be higher, compared to a similar composite where a crude oil based resin is used. The polyester resin was initiated by a free radical peroxide, 2 wt-\% methyl ethyl ketone peroxide (MEKP). To activate the initiator, $1 \mathrm{wt}-$ $\%$ cobalt octoate was mixed with the resin before adding the peroxide.

The reinforcements used were two different types of viscose fabrics, a non-woven viscose fabric (NWF), and a uniaxial warp-knitted fabric (UF), see Figure 1. The nonwoven fabric was inserted in the middle of the lay-up as a core to give a sandwich type of laminate. This configuration is beneficial, as a sandwich layup consisting of two 
mechanically stiffer surface layers with a less stiff core component can provide enhanced properties under flexural bending conditions. The non-woven viscose fabric was supplied by Suominen Nonwovens, Finland, and it is made from randomly distributed 1.7 dtex viscose staple fibres. The non-woven fabric is approximately 0.25 $\mathrm{mm}$ thick, and has fibre areal weight of $50 \mathrm{~g} / \mathrm{m}^{2}$. This non-woven is commonly used in hygienic products such as disposable towels. As the main reinforcement component located in the laminate surface layers, a warp-knitted uniaxial viscose fabric made by Engtex, Sweden was used. This is a non-crimp fabric, with uniaxially oriented weft yarns bound together with the warp yarn. The fabric has been developed for composite applications where toughness is required. The weft yarn is a 2440 dtex Cordenka yarn with twist Z40 and composed of 1350 filaments. The warp yarn is a thin polyester yarn. The weft yarn is the main reinforcing component, while the warp yarn has no reinforcing effect. The surface weight of the fabric is $238 \mathrm{~g} / \mathrm{m}^{2}$, and the thickness is approximately $0.4 \mathrm{~mm}$.

\subsection{Lay-up of reinforcements}

Four different types of sandwich composite configurations were used and their detailed compositions are illustrated in Table 1 and the laminate lay-up is shown in Figure 2. The total reinforcement weight ratio varied from $22 \mathrm{wt}-\%$ for the sandwich laminate SL1 with one uniaxial fabric in each of the surface layers, and to $40 \mathrm{wt}-\%$, for the sandwich laminate SL4 with 3 non-woven fabrics in the core layer. SL2 and SL3 had intermediate reinforcement weigh ratios, $27 \mathrm{wt}-\%$ respective $34 \mathrm{wt} \%$. The lay-up configurations were selected so that same thickness of the laminates were obtained in the vacuum infusion mould used. By using this lay-up, a set of sandwich laminates were obtained were the weight ratio of the uniaxial non-crimp fabrics increased from laminate SL1 (9 wt-\%) to laminate SL4 (37 wt-\%).

\subsection{Composite fabrication}

The sandwich composites were fabricated using vacuum infusion (VI) moulding system obtained from Composite Integration, United Kingdom. The VI mould is composed of two parts: an aluminium bottom part and a toughened glass upper part with silicone sealants in-between. The mould can be heated by circulating heating oil in the bottom part. The mould cavity size was $200 \times 200 \times 4 \mathrm{~mm}$, and the mould surfaces were polished with a release agent in order ensure easy demoulding. For all laminates, the 
fabrics were cut into dimensions of $200 \times 200 \mathrm{~mm}$. The non-woven fabrics and the warp-knitted fabrics were arranged as shown in Figure 2. The mould was then closed tightly, and connected to a vacuum pump to give a vacuum around $100 \mathrm{kPa}$. The resin was prepared by first adding 2 wt.- $\%$ of MEK peroxide and then deaerating the mixed resin by vacuum. The mould was then connected to the resin pot by tubes from two opposite corners, as shown in Figure 3. This infusion direction was found as the most efficient, after some pre-trials. The resin infusion could be followed through the transparent upper glass mould, and the infusion was continued until complete mould filling. The polyester resin was then cured by heating the mould to $50{ }^{\circ} \mathrm{C}$ for 2 hours, and under vacuum. After this, the laminates were demoulded, and put in an oven for additionally 24 hours at $50{ }^{\circ} \mathrm{C}$ in order to post-cure. The procedure was repeated 3 times for each laminate lay-up in order to ensure a reproducible processing, and also to obtain sufficient specimens for the mechanical testing.

\subsection{Testing and characterisation}

\subsubsection{Tensile and flexural testing}

Tensile and 3-point bending flexural tests were performed on a Tinius Olsen H10KT universal testing machine equipped with a $100 \mathrm{R}$ mechanical extensometer and a $5 \mathrm{kN}$ load cell. The tests were conducted accordance with the ISO 527 standard for tensile characteristics and the ISO 14125 standard for flexural characteristics. The loading rate of $10 \mathrm{~mm} / \mathrm{min}$ was used for both tests. The specimens were cut to the dimensions given by the standards using a laser cutting machine (GCC, Laserpro Spirit, the Netherlands). The specimens were then conditioned for $24 \mathrm{~h}$ at $50 \%$ relative humidity and the temperature of $23{ }^{\circ} \mathrm{C}$. At least 5 specimens from each laminate were tested immediately after conditioning and an average was taken.

\subsubsection{Low velocity impact test}

Zwick/Roell HIT230F instrumented falling weight drop impactor was used to perform a low-velocity instrumented falling weight impact testing. The specimens were cut by laser from the sandwich laminates to a specimen size of $70 \times 70 \mathrm{~mm}$. Four specimens were tested per each composite category. The impactor mass was $23.11 \mathrm{~kg}$ (weight of tup $0.278 \mathrm{~kg}$ and weight of the impactor mass of $22.832 \mathrm{~kg}$ ), which generated an incident energy of 25 Joules for each impact which was achieved by dropping the mass from $110 \mathrm{~mm}$ height at room temperature. The diameter of the hemispherical steel tup was 
$19.8 \mathrm{~mm}$. Impact parameters such as peak force, absorbed energy and displacement were continuously recorded for every specimen at each impact event performed using a load cell and a strain-gauge striker fitted on the system. The impact testing system was also equipped with an anti-rebound device to prevent the multiple impacts on the specimens. The specimens were clamped using rigid clamping plates. An overview of drop weight impact mass, hemispherical impact tup and clamping systems are presented in Figure 4.

\subsubsection{Fractured surface characterisation by SEM}

The images of fractured surfaces of the impacted sandwich composites were acquired and analysed using a Phillips XL30CP scanning electron microscope (SEM). The samples were metallised using pre-coated, thin gold film in a vacuum and the micrographs were obtained at a voltage of $15 \mathrm{kV}$.

\section{Results and discussion}

The tensile, flexural and the low velocity impact behaviours of the unsaturated polyester sandwich composites SL1 to SL4 have been studied experimentally. The influence of the different lay-up configurations of uniaxial warp-knitted and non-woven fabrics and their weight ratios in the sandwich on the tensile, flexural and impact properties including load bearing capability, energy absorption, impact damage characteristics from the falling weight impact are discussed in the following sections. These results are then further interpreted by SEM analysis of the fractured surfaces.

\subsection{Tensile strength and modulus}

The tensile strength and modulus of the sandwich composites are depicted in Figure 5. The tensile strength shows an increasing trend from $50 \mathrm{MPa}$ for laminate SL1 to a significantly increased strength of $160 \mathrm{MPa}$ for SL4 with the highest reinforcement weight fraction, $39.8 \mathrm{wt}-\%$. This increase in strength is attributed to the fibre weight fraction as well as increased ratio of the stiffer uniaxial fabric ratio. The tensile strength follows quite clearly the uniaxial warp knitted fabric content, which is 9.3 wt- $\%$ for laminate SL1, and $36.9 \mathrm{wt}-\%$ for laminate SL4. It evident that uniaxial fabric resulted in a significant increase of tensile strength, and SL4 could be considered as a laminate consisting of only the uniaxial fabric. This is expected as the higher mechanical strength was achieved due to the uniaxial orientation of the fabrics in the laminate. 
It is evident from Figure 5 (b) that the tensile modulus does not follow a trend similar to tensile strength. The tensile modulus recorded approximately from $7 \mathrm{GPa}$ for laminate SL1, $8 \mathrm{GPa}$ for laminate SL2 and SL4 and $9 \mathrm{GPa}$ for laminate SL3. The increased amount of uniaxial fabric content has contributed in higher modulus, as expected. The standard deviation for the modulus is rather large, which can be attributed to variation in fibre alignment in the surface layers. It is established that when fibre alignment is not perfect, the cut fabrics will be compressed in the mould upon closure, and then the longitudinal uniaxial orientation is partly lost. This is a draw-back in the used processing by vacuum infusion in a rather small size mould.

The elongation at max force is approximately $9 \%$ for all the laminates with the higher uniaxial fabric loading. This is well in line with the elongation values for neat viscose fibres, $15.4 \pm 2.3$ which has been reported [31]. The laminate SL1, shows a very low tensile elongation, around $1 \%$. This was seen as a brittle fracture behaviour for this laminate compared to the other laminates, and it shows the poor reinforcing effect of this type of non-woven fabric. The laminate consisted of only one uniaxial fabric in the surface layers, and these alone will not give sufficient tensile strength.

\subsection{Flexural strength and modulus}

The flexural behaviour of the sandwich laminates is shown in Figure 6. The flexural strength follows a trend similar to tensile strength can be observed. The laminates SL2, SL3 and SL4 exhibited an average flexural strength around 169, 183, $186 \mathrm{MPa}$, respectively. As it was observed for tensile modulus, the flexural modulus was almost the same for the specimens SL2 - SL4 with higher uniaxial fabric loading, approximately between $7-8 \mathrm{GPa}$. The elongation at break is also similar for these laminates, approximately $6 \%$. This shows that the laminate lay-up behaves as expected for a sandwich structure as an improved flexural strength is achieved with a total reinforcement weight ratio of $27.1 \mathrm{wt}-\%$ for SL2. The laminate SL1 behaved in a similar manner in the bending test as it was for the tensile, and has a clearly lowest flexural strength and modulus, around $114 \mathrm{MPa}$ and $6 \mathrm{GPa}$, respectively, while the elongation at break is approximately $3.5 \%$, nearly half the value compared to the other laminates. The same conclusion regarding the reinforcing effect of the non-woven fabric can be made as for the tensile properties.

\subsection{Low velocity impact properties}




\subsubsection{Force displacement traces}

Force against displacement curves obtained from the low-velocity impact testing for different specimens are illustrated in Figure 7. From these curves, it can be seen a strong relationship between the peak force and fibre configuration and ratios. The peak force for laminate SL1 has been recorded at approximately $3690 \mathrm{~N}$, under the low velocity parameters used, the drop weight penetrated this specimen, and this is also shown by an unstable displacement indicating early delamination initiation. The forcedisplacement curves for sandwich laminates SL2, SL3 and SL4 follow a more stable propagation than that of for SL1. The increased uniaxial fabric ratio increased the impact force and with a lower displacement. The increase in displacement despite the reduction on force for less uniaxial fabric contained specimens is attributed to the higher loading of the ductile staple fibres in the non-woven fabrics located in the sandwich core.

The results show that the higher the percentage of uniaxial warp-knitted reinforcement in the surface layers, the stronger the composite sandwich become, which can be attributed to the uniaxial and non-crimp structure of the warp-knitted reinforcements. The laminate SL2 with 2 layers of uniaxial fabric in the surface layers has a peak force of approximately $4740 \mathrm{~N}$, laminate SL3 with 3 layers of uniaxial fabric in surface layers has recorded approximately $5160 \mathrm{~N}$ as the peak force, and the laminate SL4 with 4 layers of uniaxial fabric in surface layers has recorded the highest result approximately at $5390 \mathrm{~N}$. The uniaxial warp-knitted fabrics overlaying each other acts as strong points in the surface layers of the composite sandwich, resisting failure by absorbing and dissipating energy. The lower elongation at break for higher uniaxial warp-knitted content sandwich laminates suggests that uniaxial warp-knitted fibre configuration contributed to the increased stiffness of composite sandwich, as indicated by superior load bearing capabilities.

\subsubsection{Force-time comparisons}

The force-time traces corresponding to impact event for each specimen subjected to incident energy of 25 Joules is illustrated in Figure 8. Force is generally defined as reaction force exerted by the specimen to the impactor. As shown, the maximum force increased with the increase in uniaxial warp-knitted fibre content. The force time curves for all specimens are mountain-like, almost parabolic. In the case of laminate SL1, it is 
noticeable that there is an early load drop which corresponds that there is unstable early delamination. As the contents of uniaxial warp-knitted fabric increased, the height of the mountain like curves also increase. The time taken to complete the impact event is different for each laminate. It is evident that the higher weight percent of warp-knitted fabric in the sandwich surface layers give a better impact resistance, hence taken longer time to complete the impact event compared to lower uniaxial warp-knitted content laminates. The laminate SL1 has shown that the failure and initial damage occurred over a shorter time than that of higher reinforcement loaded laminates. As shown in Figure 8, it is evident from the test-time traces that there is a strong relationship between composite lay-up configuration and overall materials strength. Laminate SL1with 9.3 wt.-\% warp-knitted fabric and 12.7 wt.- $\%$ non-woven fabric exhibiting the lowest test time shows that this lay-up was the weakest one as it had the least amount of time in contact with the impactor, and failing shortly after the impact. It is interesting to note the correlation between the fibre weight percentage and configuration for each of the system investigated. The non-woven fibres aligned in a non-uniform random manner did not achieve high peak load, and limits its stiffness and strength. Test time, which is impact event, gradually increases as the percentage of uniaxial warp-knitted fabric increased.

\subsubsection{Energy-time comparisons}

Typical absorbed energy versus time plots for different laminates is depicted in Figure 9. It is clear from the figure that laminate SL1 fractured as the peak energy, corresponding to the maximum value, did not reach as high as for other samples. This shows that when this laminate is being impacted at the incident energy of 25 Joules, the structure was fully penetrated. This is due to the low percentage of non-woven fabric in the core allowing the energy to pass through and not be absorbed. Whereas, the specimens made from the warp-knitted and non-woven laminate configurations designated as SL2, SL3 and SL4 did not puncture upon impact energy of 25 Joules as evidenced showing lower energy absorbed and higher recovered energy. In the case of SL1 plate, all the incident energy was absorbed showing no recovery energy, as the damage was fully penetrated. The absorbed energy decreases with increase in recovery energy for warp-knitted and non-woven plates as illustrated in Table 2, exhibiting improved impact performance. 


\subsection{Impact damage and failure modes}

Post impact damage images of the sandwich laminates are presented in Figures 10 and 11. The visual inspection of impacted specimen SL1 (Figure 10 a) clearly shows that the specimens have undergone fully penetration damage, as the impactor has pierced straight through. Because of this nature of failure, all modes of failure seemed to have occurred. It is clear that matrix cracking, fibre breakage at the rear face fibre pull outs, and delamination are present. Large chunks of the matrix have sheared out of the sample showing how it delaminated.

Fibres around the main impacted entrance hole show that fractured and pulled fibres were unable to withstand the impact force. The matrix seemed to have shattered in a brittle manner, and material loss (spalling) was observed. A fairly obvious circular hole was present when looking at both front and rear faces, showing severe damage from the impactor tup. This confirms the poor impact performance of the non-woven fabric as composite reinforcement.

For impacted specimens SL2, SL3 and SL4 (Figure $10 \mathrm{~b}-\mathrm{d}$ ), the damage area and size of SL2 shows larger than for SL3 and SL4. The damage spread is similar, all showing roughly the similar pattern. A shockwave like effect is clear to see on the impacted faces of these samples, where the impacted energy was spread throughout the face within the warp-knitted fabrics.

The rear faces of all specimens show similar damage propagation, however, large penetration hole and fibre shear out were visible for SL1 (Figure 11 a). For the other specimens, crack was clearly visible (Figure $11 \mathrm{~b}$-d), showing rupture as well as delamination of fibres. The extent of damage seems larger for samples with low weight ratio of warp-knitted fabric configuration.

Additionally, elongated shape like damage cracks are presents on the impacted and rear faces of specimens SL2, SL3 and SL4, respectively, showing the shockwave of the impacted energy being spread throughout the face of the samples. This shows that the energy absorbed into the non-woven face. Higher weight ratio of non-woven fabric seems allowing less deformation upon impact, showing these are more impact resistive configurations. A crack across the rear faces showing the dissipation of energy through the sample not being fully absorbed by the fibres, and again cracking the brittle unsaturated polyester matrix. 
It is clear from the results that laminates SL2 and SL3 performed very similarly in terms of absorbed energy and test times, due to very similar fibre configurations. Whereas laminate SL4 absorbed the highest energy, and under closer visual inspection, performed the best in terms of impact resistance.

\subsection{Fractured surface of impacted samples}

A representative SEM images of fractured surfaces of impact damage for different specimens at 500 magnification are shown in Figure 12. From visual inspection of the impacted 9.3 wt.-\% uniaxial fabric/12.7 wt.-\% non-woven fabric specimens SL1 (Figure $12 \mathrm{a}$ ), it is clear that matrix cracking and fibre pull outs, and delamination were present. Large chunks of the matrix seemed to have sheared out of the sample. From the SEM image, it seems that there was a weak fibre matrix interface (weak adhesion between fibre and matrix) as a result, fibre debonding and pull out damage were observed. If the interfaces are weaker than the matrix, then composite can fail in the fibre matrix interface at early stage. This may have contributed for the lowest force and the highest deformation for SL1 as evidenced by force versus displacement traces (Figure 7). For SL2 on the other hand (Figure $12 \mathrm{~b}$ ), the fractured surfaces of the unsaturated polyester matrix reveal that the fibres are exposed, unravelled and pulled out.

For SL3 (Figure $12 \mathrm{c}$ ), the matrix was cracked and the fibres were bended and fractured. The higher ratio of warp-knitted cellulose fibres onto unsaturated polyester matrix has contributed to the improved properties compared to other samples such as SL1 and SL2 evidenced by higher impact force and improved penetration resistance. The fractured surface of SL4 is shown in Figure 12 d. It was observed that unsaturated polyester matrix has cracked in a brittle fashion and some bundles of fibres are exposed. Although the fibres are exposed, they are not pulled out as it was for SL1 and as a result, contributed moderately improving load bearing capability.

SEM representation image of SL1 specimen at the higher magnification is illustrated in Figure 13. It is clear from the SEM images that delamination and fibre pull out are the predominant failure modes for higher non-woven contained specimens, whereas for higher warp-knitted contained specimens, matrix cracking, fibre bending and breakage are the main failure modes.

\section{Conclusions}


The work presented in this study investigated the mechanical properties of viscose sandwich composites composed of uniaxial warp-knitted viscose fabrics as surface layers and non-woven viscose fabrics as the sandwich core. The aim was to investigate if a low cost randomly oriented non-woven viscose fabric could be used as a component in structural composites. This non-woven fabric was placed between layers of uniaxial non-crimp fabrics, so that a sandwich type laminate was obtained. By combining a higher cost and high performing fabric, with a low cost fabric, it was possible to reduce the overall costs, without a major sacrifice of mechanical performance, if the loading of the non-woven fabric is not too high, as was the case for laminate SL1. Combining the percentage of uniaxial warp-knitted and non-woven fabrics with varying configurations was found to be effective for improved impact resistance behaviour. It was evident from the results that samples with higher uniaxial fibre weight and configuration can withstand a significantly higher force.

The tensile test results showed that sandwich laminates SL2, SL3 and SL4 exhibited acceptable tensile strength and tensile modulus, which should meet most common composite application specifications. Their performance could be further enhanced by increasing the overall reinforcement loading. The laminate SL1 exhibited a low tensile strength at break, and a low elongation at maximum loading. This laminate configuration was shown not sufficient for any structural applications.

From the low velocity impact test results, a significant increase in peak force was found at the higher warp-knitted fibre percentage. Sandwich laminate SL4 recorded the highest peak force of approximately $5390 \mathrm{~N}$. This was due to the highest weight ratio of the uniaxial reinforcement (36.9 wt.-\%) having strong cross over points within the composite being able to absorb higher impact energy and dissipating it more evenly through fibres. The maximum peak force decreased with fibre weight, as laminates SL3, SL2 and SL1 recorded 5160, 4740 and 3690 N respectively.

The higher content and configuration of uniaxial warp-knitted samples in combination with non-woven reinforcement not only exhibited better impact damage resistance but also provided enhanced tensile and flexural properties. From the experimental results, it can be concluded that the combination of a warp-knitted uniaxial fabric with low cost non-woven fabric can provide suitable cost effective biocomposites with good mechanical performance, which provide significant cost-property benefits in many engineering applications. 


\section{Acknowledgements}

Sylwia Wojno and Coline Mabille are gratefully acknowledged for assisting in the manufacture of the laminates and their characterisation.

\section{Funding}

This research did not receive any specific grant from funding agencies in the public, commercial, or not-for-profit sectors.

\section{REFERENCES:}

1. Faruk, O., Bledzki, A.K., Fink, H.P., \& Sain, M. Biocomposites reinforced with natural fibres: 2000-2010. Progress in Polymer Science, (2012) 37, 15521596.

2. Mohanty, A. K., Misra, M., Hinrichsen, G. (2000). Biofibres, biodegradable polymers and biocomposites: An overview. Macromol. Mater. Eng.; 276/277:124.

3. Dhakal, H. N., Zhang, Z. Y., \& Richardson, M. O. (2007). Effect of water absorption on the mechanical properties of hemp fibre reinforced unsaturated polyester composites. Composites Science and Technology, (2007) 67, 16741683.

4. Adekunle K, Åkesson D, Skrifvars M. Biobased composites prepared by compression molding with a novel thermoset resin from soybean oil and a natural-fiber reinforcement. Journal of Applied Polymer Science 2010; 116: $1759-1765$.

5. Summerscales, J., Dissanayake, N. P. J., Virk, A. S., and Hall, W. (2010). A review of bast fibres and their composites. Part 1 -Fibres as reinforcements. Composites Part A, 41, 1329-1335.

6. Paul, V., Kanny, K., Redhi, G. G. Mechanical, thermal and morphological properties of a biobased composite derived from banana source. Composites Part A: Applied Science and Manufacturing 2015; 68:90-100.

7. S.V Joshi, L.T. Dzal, A.K. Mohanty, S. Arora. "Are Natural Fiber Composites Environmentally Superior to Glass Fiber Reinforced Composites?" Composites Part A, 35 (2004). Pp371-376 
8. Dhakal, H.N., Sarasini, F., Santulli, C., Tirllo, J., Zhang, Z., Arumugam, V. Effect of basalt fibre hybridisation on post-impact mechanical behaviour of hemp fibre reinforced composites. Composite Part A, 2015; 75:54-67.

9. Thakur, V.K, Thakur, M.K. Processing and characterisation of natural cellulose fibres/thermoset polymer composites. Carbohydr Polym 2014; 109:102-117.

10. Directive 2000/53/EC of the European Parliament and The Council For Endof-life Vehicles, Official Journal of the European Communities, Oct 21, 2000, ABl.EG Nr. L 269 S. 34L 269/34

11. Molker, H., Gutkin, R., Asp, L.E.. Implementation of failure criteria for transverse failure of orthotropic non-crimp fabric composite materials, Composite Part A 2017; 92:158-166.

12. N. C. Guerraz, M. J. Dumont, Hubert, H. Environmental resistance of flax/biobased epoxy and flax/polyurethane composites manufactured by resin transfer moulding. Composite Part A 2016; 88: 140-147.

13. Sy, B.L., Fawaz, Z., Bougherara, H. Damage evolution in cross-ply flax/epoxy laminates subjected to low velocity impact loading. Composites Part A, 2018;112:452-467.

14. Fiore, V., Scalici, T., Tirillo, J., Calabrese, L. Salt-fog spray aging of jutebasalt reinforced hybrid structures: Flexural and low velocity impact response. Composites Part B; 2017;116:99-112.

15. Dhakal, H.N., Skrifvars, M., Adekunle, K., Zhang, Z.Y. Falling weight impact response of jute/methacrylated soybean oil bio-composites under low velocity impact loading. Composite Science and Technology, 2014; 92:134-141.

16. Sarasini, F., Tirillo, J., Valente, M., Valente, T., Iannace, S., Sorrentino, L. Effect of basalt fibre hybridisation on the impact behaviour under low impact velocity of glass basalt woven fabric/epoxy resin composites. Composites Part A 2013; 47:109-123.

17. Bledzki, A.K., Franciszczak, P., Meljon, A. High performance hybrid PP and PLA biocomposites reinforced with short man-made cellulose fibres and 
softwood flour. Composites Part A: Applied Science and Manufacturing 2015; 74:132-139.

18. Ramamoorthy, S.K., Kundu, C.K., Adekunle, K., Bashir, T, Skrifvars, M. Properties of green composites with regenerated cellulose fibre and soybeanbased thermoset for technical applications. Journal of Reinforced Plastics and Composites, 2013;33:193-201.

19. Carillo, F., Colom, X., Canavate, X., Properties of regenerated cellulose lyocell fiber-reinforced composites. Journal of Reinforced Plastics and Composites, 2010;29:359-371

20. Ganster, J., Fink, H.-F., Uihlein, K., Zimmerer, B., Cellulose man-made fibre reinforced polypropylene- correlations between fibre and composite properties. Cellulose, 2008;15:561-569

21. Graupner, N., Rössler, J., Ziegmann, G., Mussig, J., Fibre/matrix adhesion of cellulose fibres in PLA, PP and MAPP: A critical review of pull-out test, microbond test and single fibre fragmentation test results. Composites: Part A, 2014;63:133-148

22. Ranganathan, N., Oksman, K., Nayak., S.K., Sain, M., Structure property relation of hybrid biocomposites based on jute, viscose and polyproplylene: The effect of the fibre content and the length on the fracture toughness and the fatigue properties. Composites: Part A, 2016;83:169-175

23. Franciszczak, P., Merijs-Meri, R., Kalnins, K., Bledzki, A.K., Zixans, J., Short-fibre hybrid polyproplylene composites reinforced with PET and Rayon fibres - Eddcts of SSP and interphase tailoring. Composite Structures, 2017;181:121-137

24. Graupner, N., Ziegmann, G., Mussig, J., Composite models for compression moulded long regenerated cellulose fibre-reinforced brittle polylactide (PLA). Composites Science and Technology, 2017;149:55-63

25. Baghaei, B., Skrifvars, M. and Berglin, L., Characterization of thermoplastic natural fibre composites made from woven hybrid yarn prepregs with different weave pattern, Composites Part A: Applied Science and Manufacturing (2015), $76: 154-161$ 
26. Shamsuddin, S.-R., Lee, K.-Y., Bismarck, A., Ductile unidirectional continuous rayon fibre-reinforced hierarchical composites. Composites Part A, 2016;90:633-641

27. Revol B.P., Thomassey, M., Ruch, F., Bouquey, M., Nardin, M., Single fibre model composite: Interfacial shear strength measurements between reactive polyamide- 6 and cellulosic or glass fibres by microdroplet pull-out test. Composites Science and Technology, 2017;148:9-19

28. Mader, A., Kondor, A., Schmid, T., Einseidel, R., Mussig, J., Surface properties and fibre-matrix adhesion of man-made cellulose epoxy composites - Influence on impact properties. Composites Science and Technology, 2016;123:163-170

29. Ramamoorthy, S.K., Skrifvars, M. and Rissanen, M., Effect of alkali and silane surface treatments on regenerated cellulose fibre type (Lyocell) intended for composites, M. Cellulose (2015), 22 (1): 637 - 654

30. Almansour F.A., Dhakal, H.N., Zhang Z.Y. Effect of water absorption on Mode I interlaminar fracture toughness of flax/basalt reinforced vinyl ester hybrid composites. Compos Struct 2017;168:813-25.

31. Adusumali, R.B., Muler, U., Weber, H., Roeder, H., Sixta, H., Gindl, W. Tensile testing of single regenerated cellulose fibres; Macromolecular Symposia, 2006; 244:83-88.

32. Fiore, V. Calabrese, L., Bruzzaniti, P., Valenza, A. Experimental design of the bearing performances of flax fibre reinforced epoxy composites by a failure map. Composites Part B 2018;148:40-48.

33. Wang, D., Onawumi, P.Y., Ismail, S.O., Dhakal, H.N., Popov, I., Silberschmidt, V.V., Roy, A. Machinability of natural-fibre-reinforced polymer composites: Conventional vs ultrasonically-assisted machining, Composites Part A, 2019;119:188-195.

34. Dhakal, H.N., Ghasemnejad, H., Zhang, Z.Y., Ismail, S.O., Arumugam, V. The post impact response of flax/UP composite laminates under low velocity impact loading. International Journal of Damage Mechanics, 2019; 28(2) 183-199. 
35. Dhakal, H.N., Bourmaud, A., Berzin, F., Almansour, A., Zhang. Z., Shah, D.U., Beaugrand, J. Mechanical properties of leaf sheath date palm fibre biomass waste reinforced polycaprolactone (PCL) biocomposites. Journal of Industrial Crops and Products, 2018;126:394-402.

36. Codou, A., Misra, M., Mohanty, A.K. Sustainable biocarbon reinforced nylon 6/polypropylene compatibilized blends: Effect of particle size and morphology on performance of the biocomposites, Composites Part A 2018, 112:1-10.

\section{Figure captions:}

Figure 1: The viscose fabrics used in the study, a) a non-woven fabric with randomly oriented fibres, b) a warp-knitted uniaxial fabric with the uniaxial weft yarns oriented in the longitudinal direction of the .

Figure 2: The used sandwich composite laminate lay-up, showing the distribution of the uniaxial warp knitted fabric in the bottom and upper surface layers and the nowwoven fabric in the middle core layer

Figure 3: The used resin injection directions in the vacuum infusion mould. The arrows show that the resin flow from the two inlet corners to the vacuum outlet in the mid part. The resin injection directions could be observed through the transparent upper mould part.

Figure 4: Drop weight impact test set up: (a) impactor mass, (b) enlarged view of impactor tup and (c) enlarged view of clamping system.

Figure 5: $(\mathrm{a}-\mathrm{c})$ : Tensile strength at max loading, tensile modulus and elongation at max loading for the biocomposite sandwich laminates.

Figure 6: $(\mathrm{a}-\mathrm{c})$ : Flexural strength, flexural modulus and flexural deformation at break for the studied biocomposite sandwich laminates.

Figure 7: Force versus displacement traces for different samples.

Figure 8: Force versus test time traces for different samples.

Figure 9: Absorbed energy versus test time traces for different samples. 
Figure 10: Visual inspection for damage patterns of different specimens impacted showing front face damage (a) SL1, (b) SL2, (c) SL3, (d) SL4.

Figure 11: Visual inspection for damage patterns of different specimens impacted showing rear face damage (a) S11, (b) SL2, (c) SL3, (d) SL4.

Figure 12: Micrographs of fractured surface obtained from SEM for different samples: (a) SL1, (b) SL2, (c) SL3, (d) >SL4.

Figure 13: SEM representation image of SL1 specimen at the magnification of x1400. 


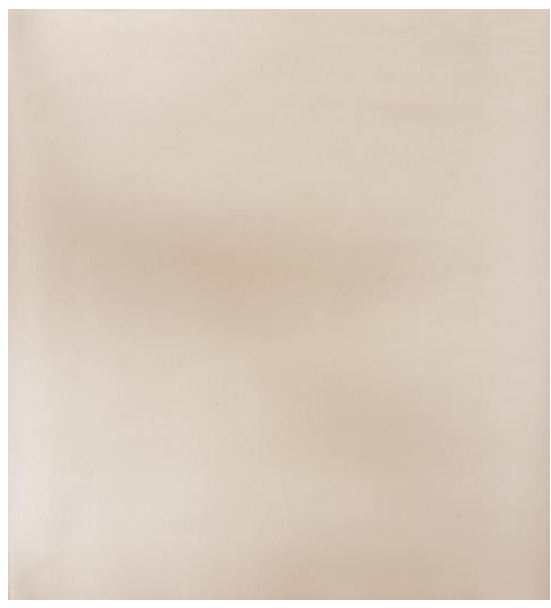

(a)

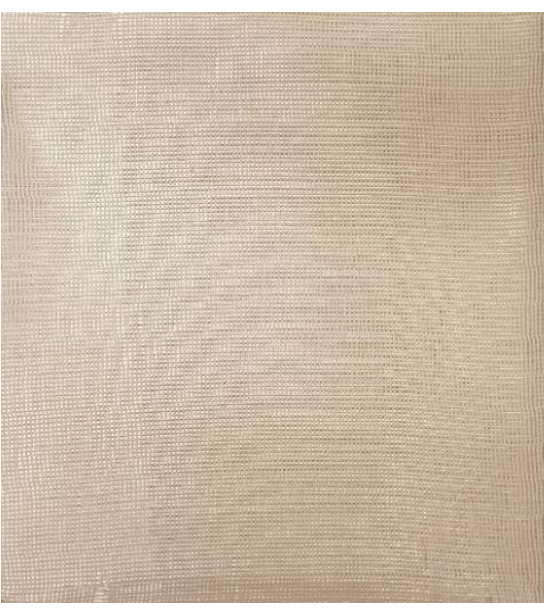

(b)

Figure 1: The viscose fabrics used in the study (a) a non-woven fabric with randomly oriented fibres, (b) a warp-knitted uniaxial fabric with the uniaxial weft yarns oriented in the longitudinal direction of the photo. 


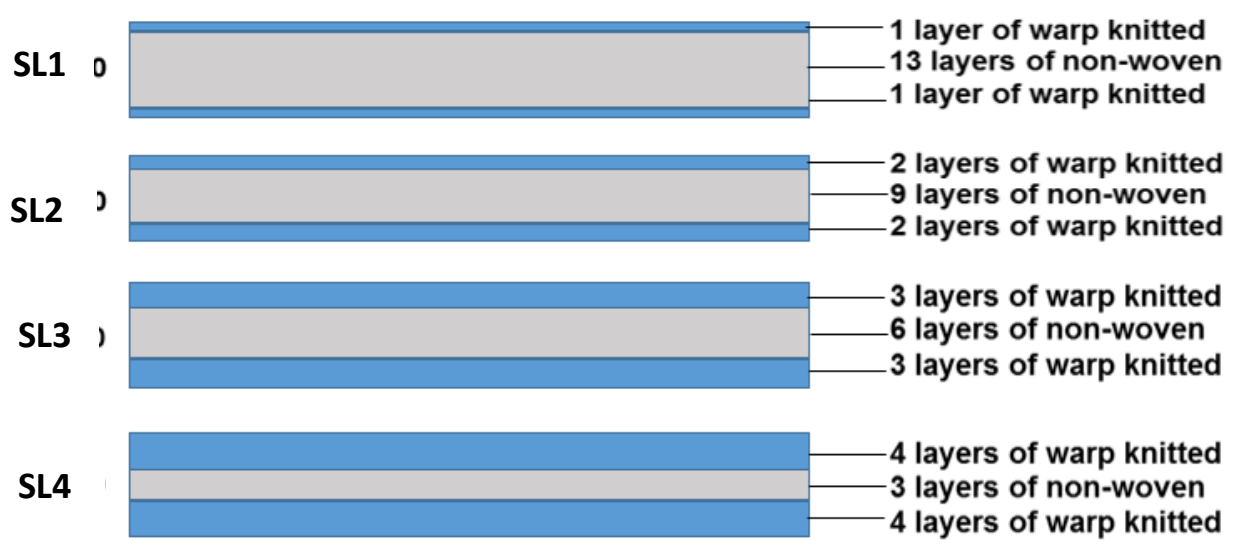

Figure 2: The used sandwich composite laminate lay-up, showing the distribution of the uniaxial warp knitted fabric in the bottom and upper surface layers and the nowwoven fabric in the middle core layer

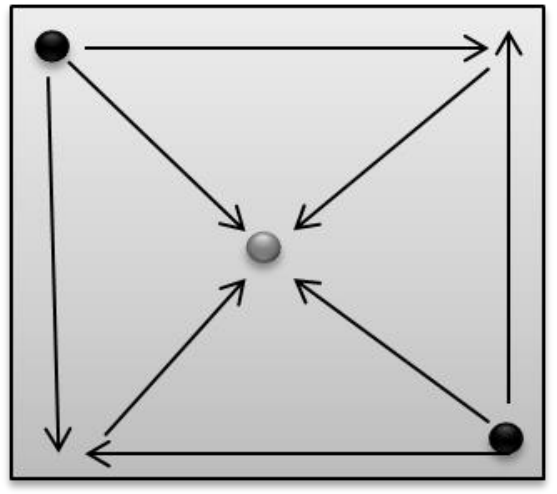

Figure 3: The used resin injection directions in the vacuum infusion mould. The arrows show that the resin flow from the two inlet corners to the vacuum outlet in the mid part. The resin injection directions could be observed through the transparent upper mould part. 


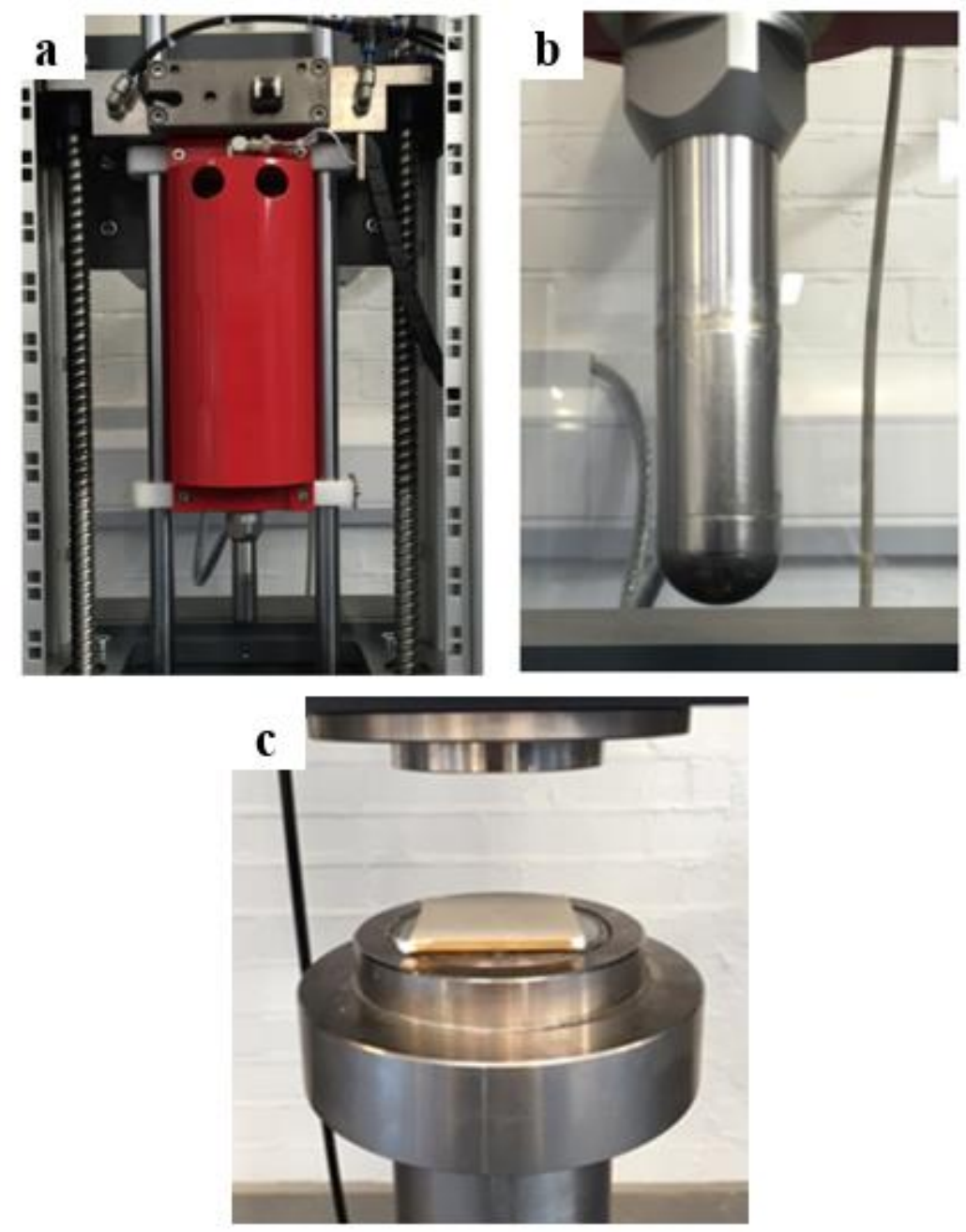

Figure 4: Drop weight impact set up: (a) impactor mass, (b) enlarged view of impactor tup and (c) enlarged view of clamping mechanism 


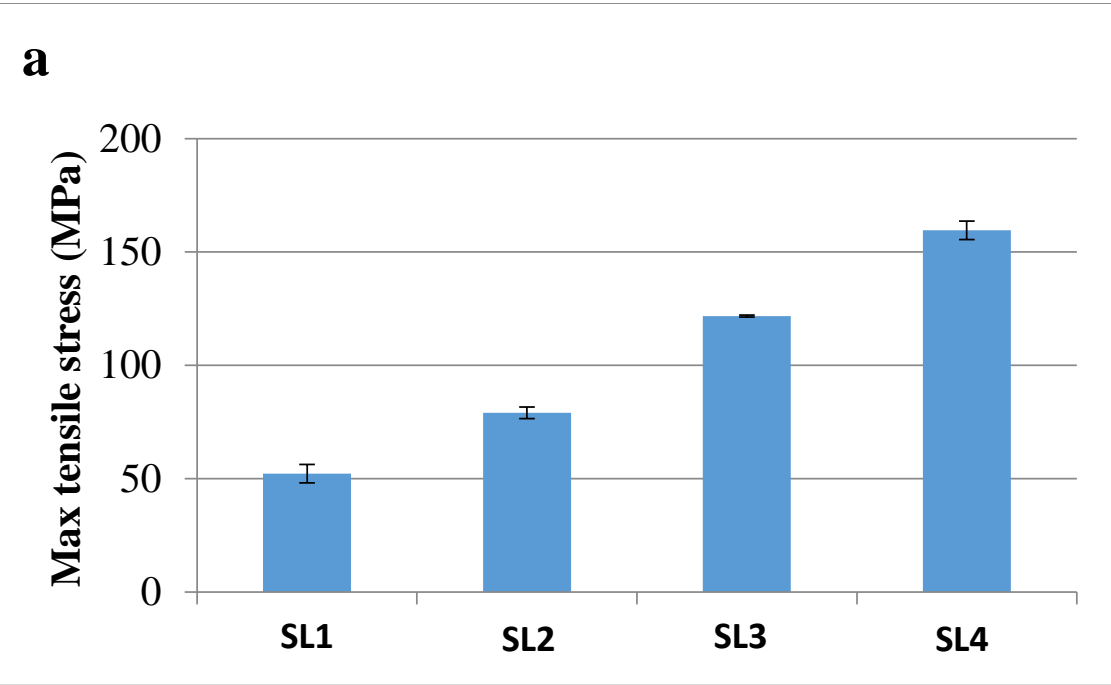

b

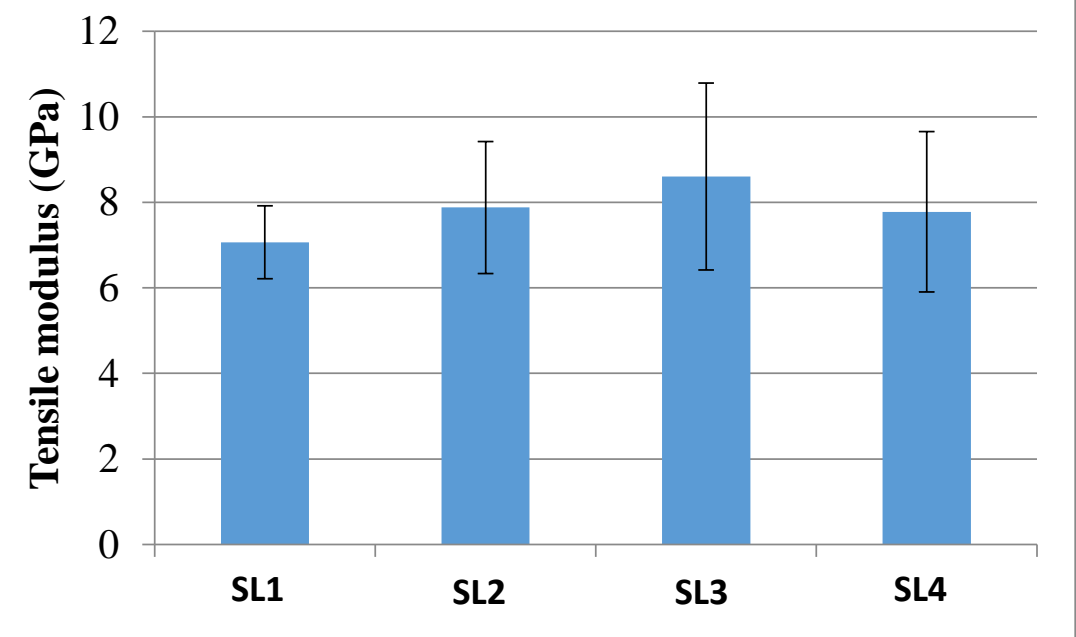

c

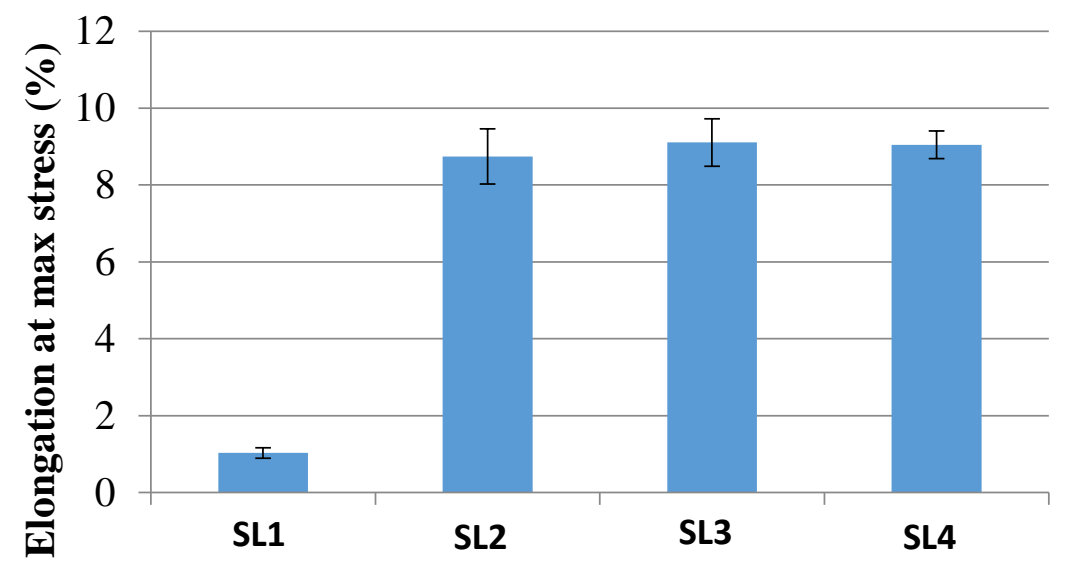

Figure $5(\mathrm{a}-\mathrm{c})$ : Tensile strength at max loading, tensile modulus and elongation at max loading for the sandwich laminates SL1 - SL4. 


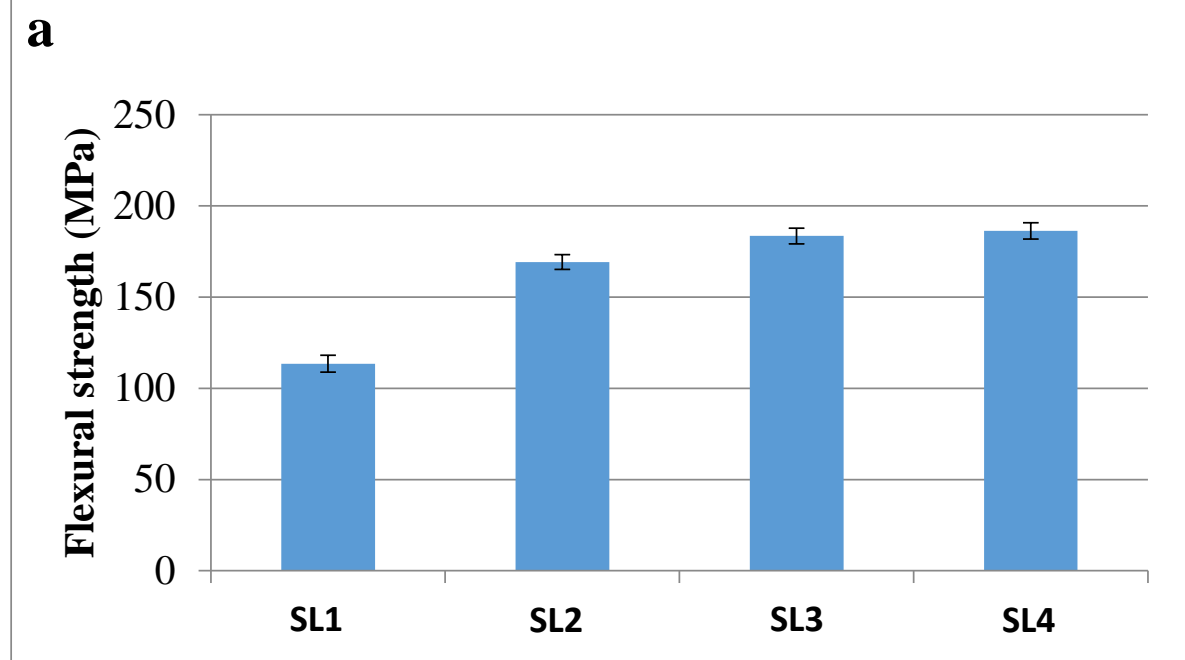

b
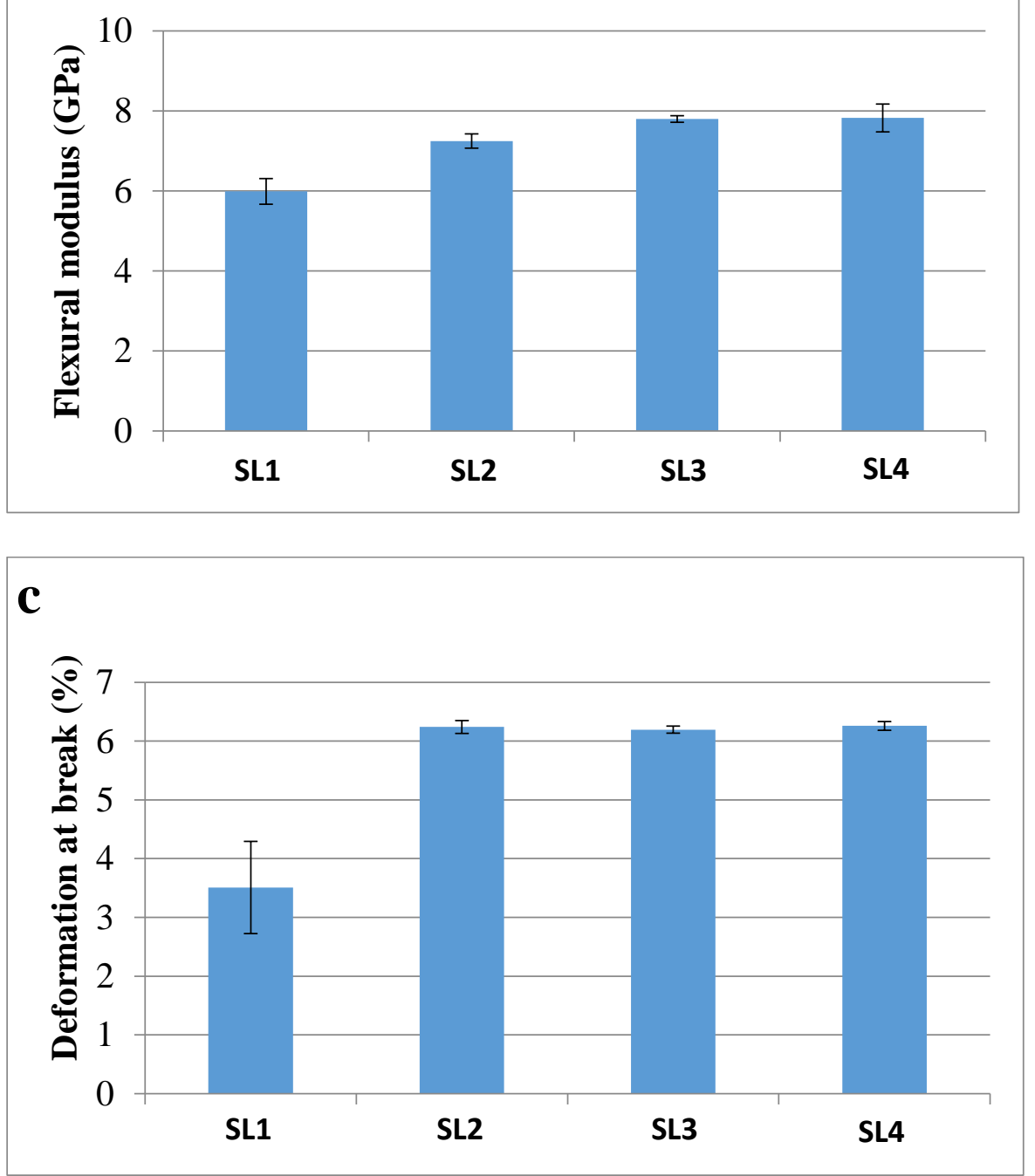

Figure $6(\mathrm{a}-\mathrm{c})$ : Flexural strength, flexural modulus and flexural deformation at break for the studied sandwich laminates SL1 - SL4. 


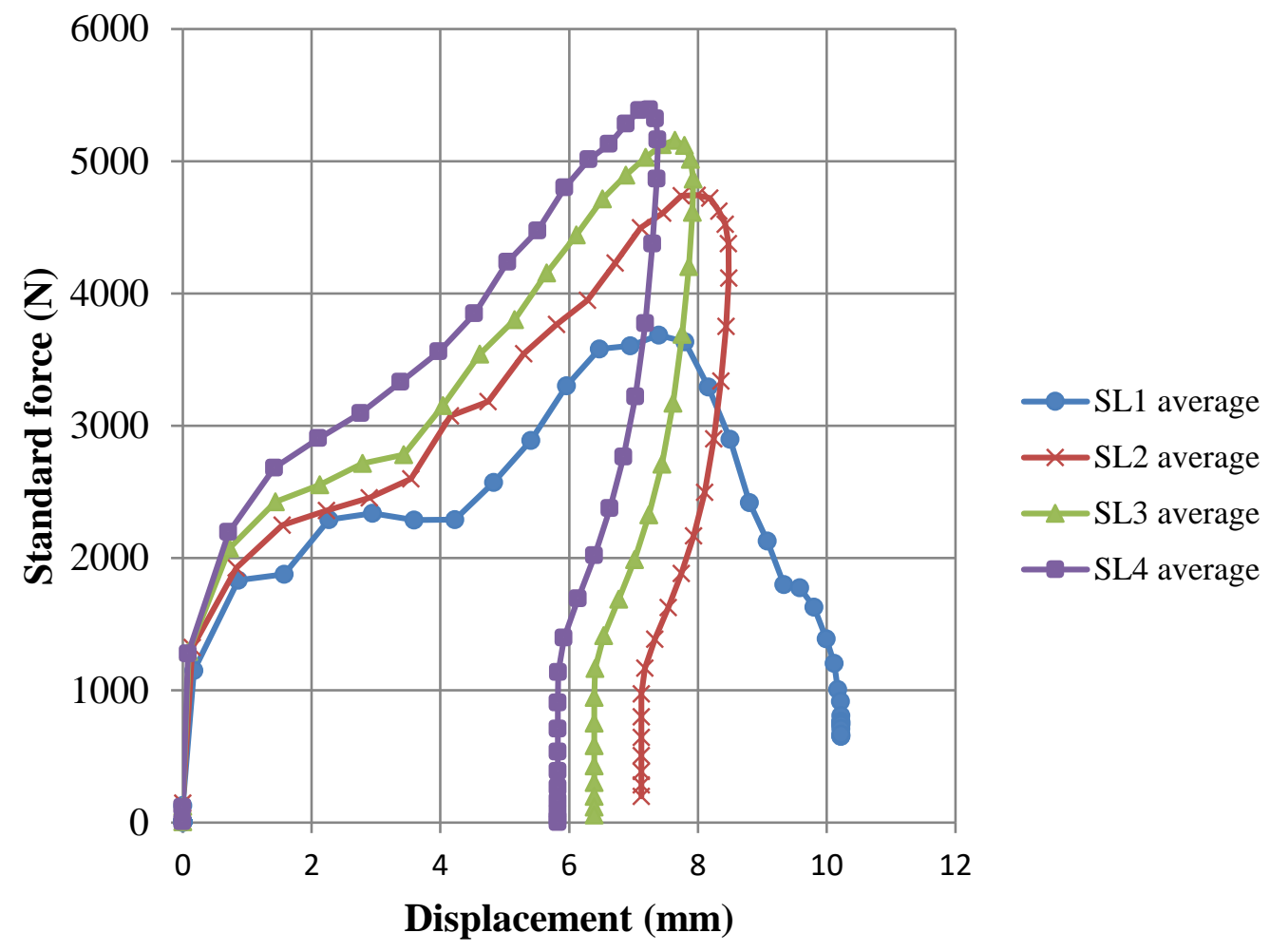

Figure 7: Force versus displacement traces for different samples

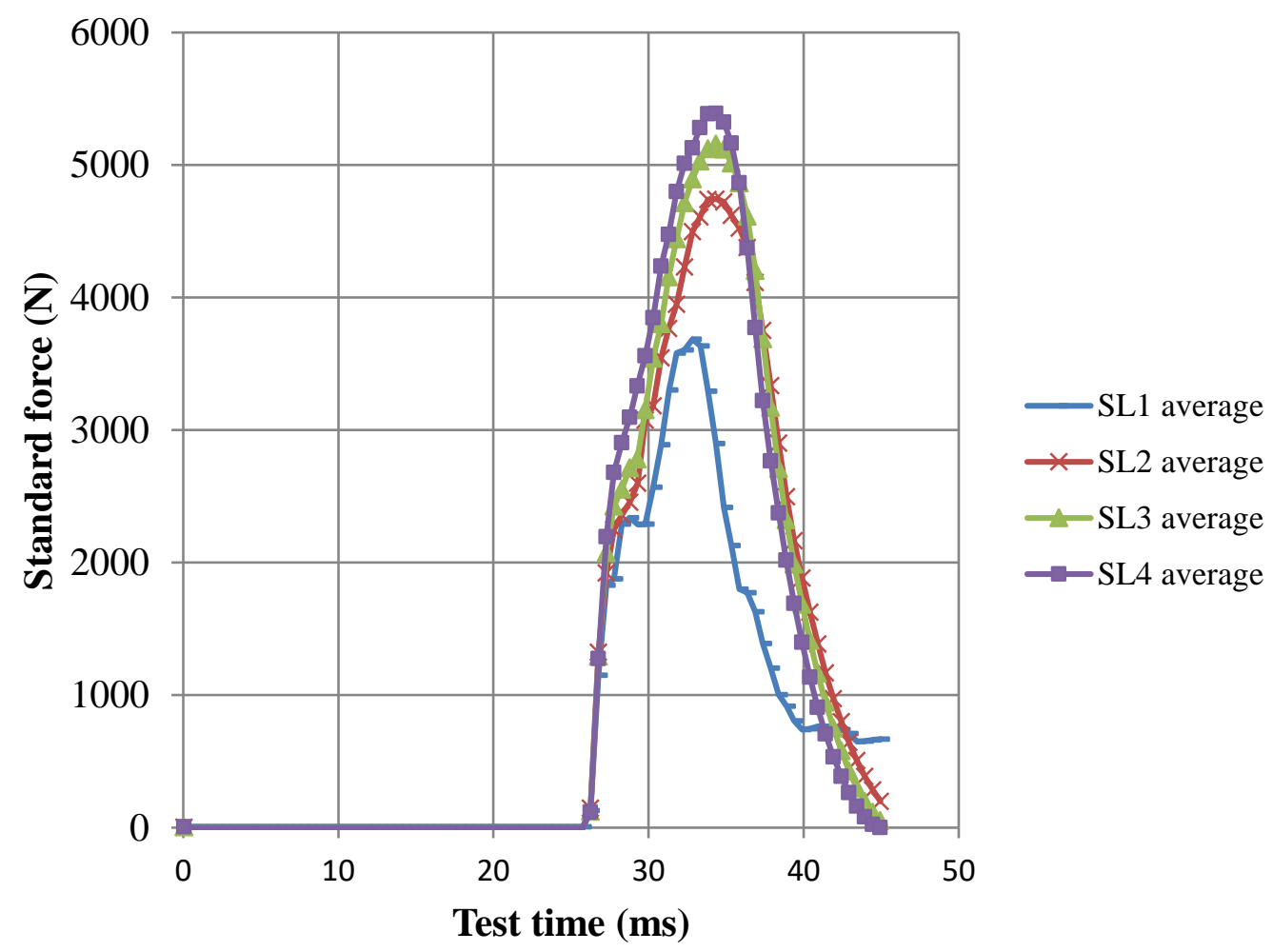

Figure 8: Force versus test time traces for different samples 


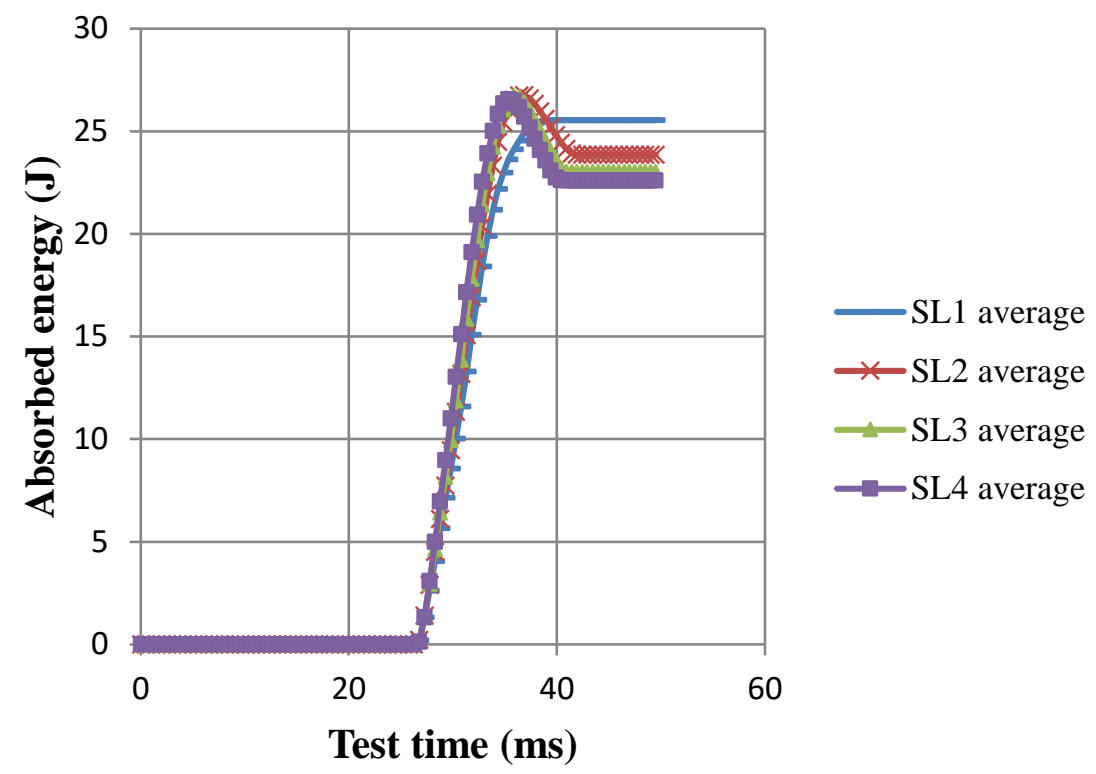

Figure 9: Absorbed energy versus test time traces

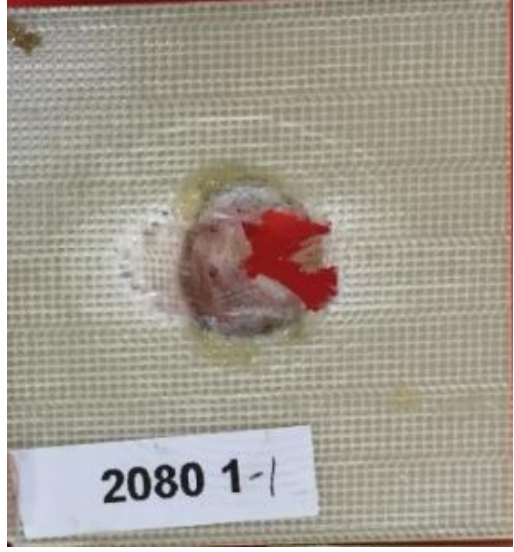

(a)

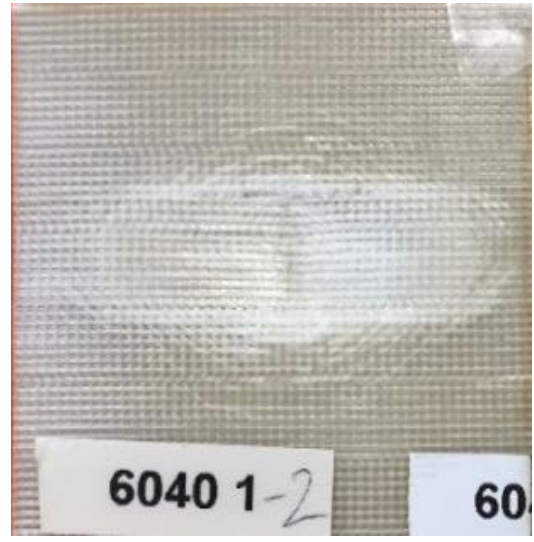

(C)

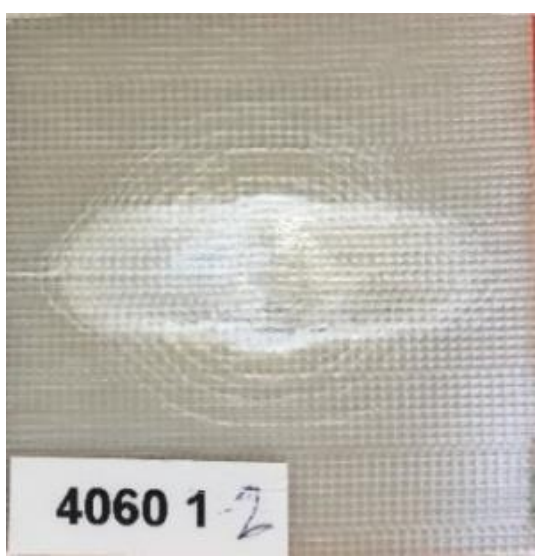

(b)

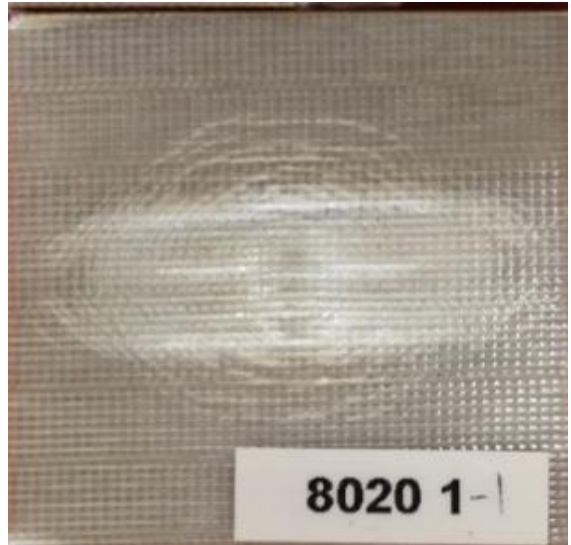

(d)

Figure 10: Visual inspection for damage patterns of different specimens impacted showing front face damage (a) SL1, (b) SL2, (c) SL3, (d) SL4 


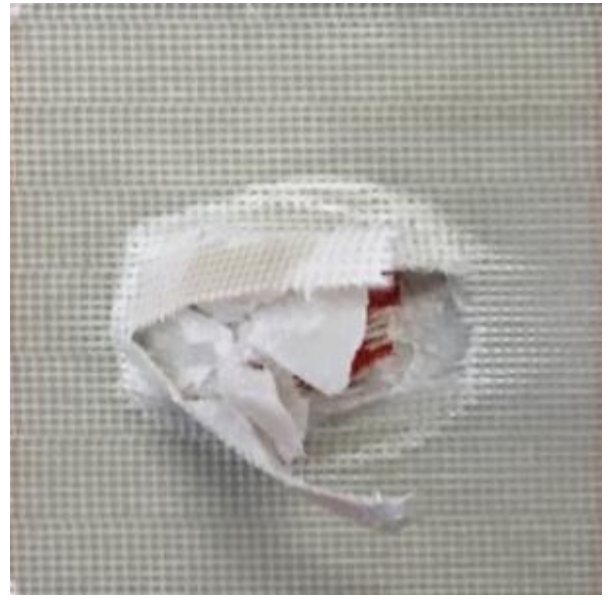

(a)

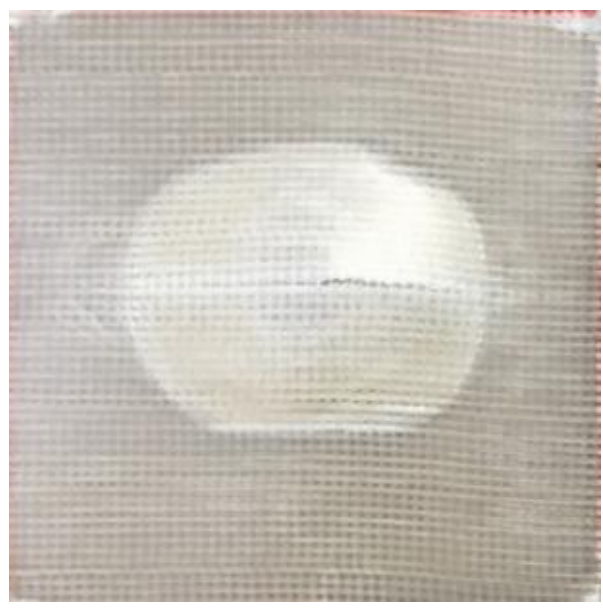

(c)

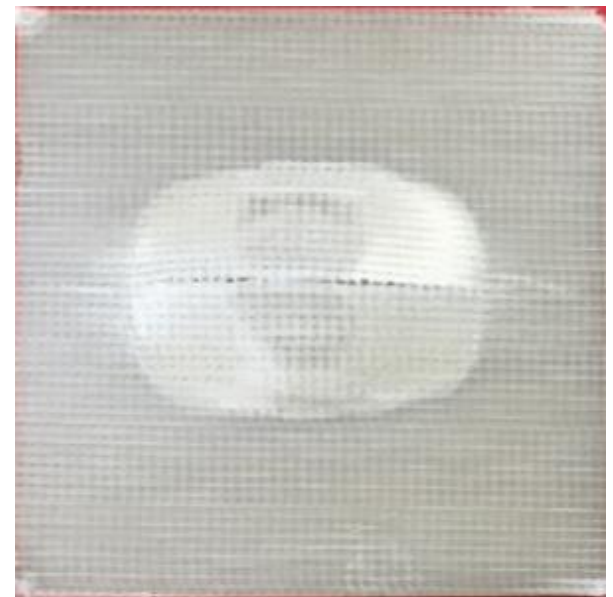

(b)

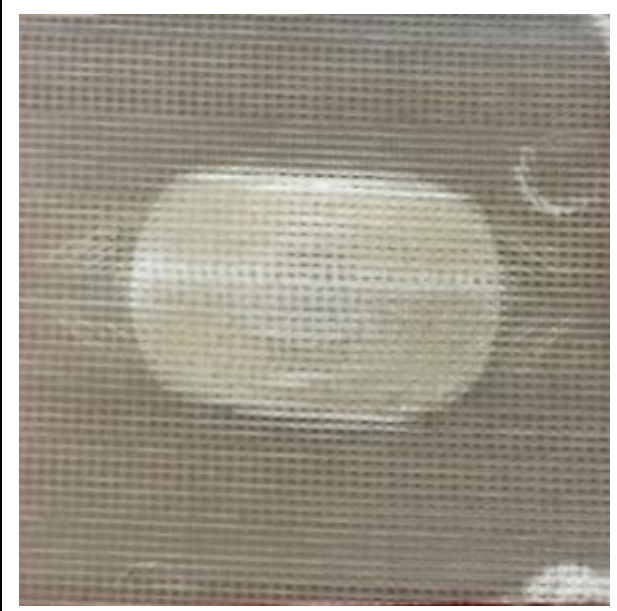

(d)

Figure 11: Visual inspection for damage patterns of different specimens impacted showing rear face damage (a) SL1, (b) SL2, (c) SL3, (d) SL4 

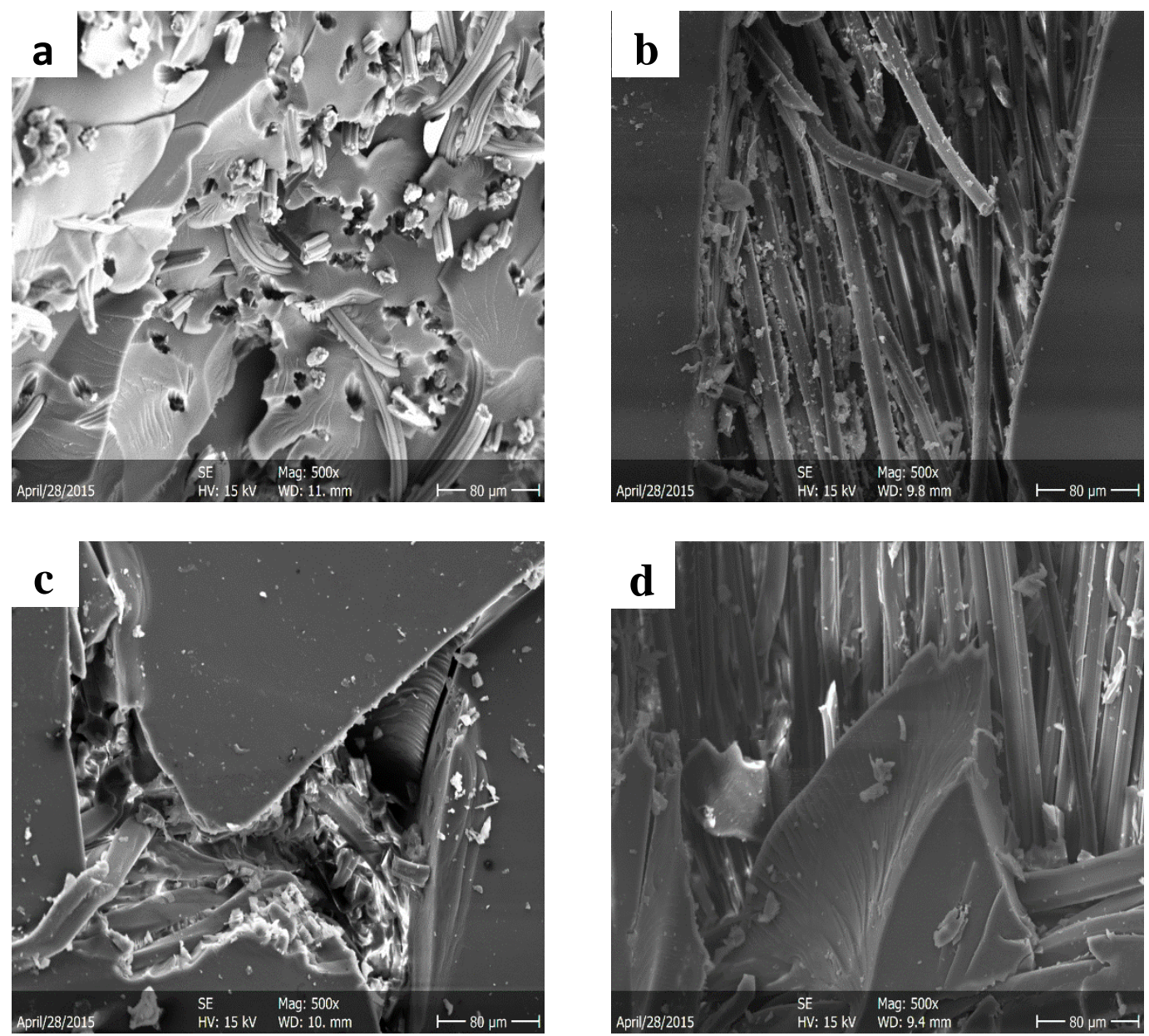

Figure 12: Micrographs of fractured surface obtained from SEM for different samples: (a) SL1, (b) SL2, (c) SL3, (d) SL4

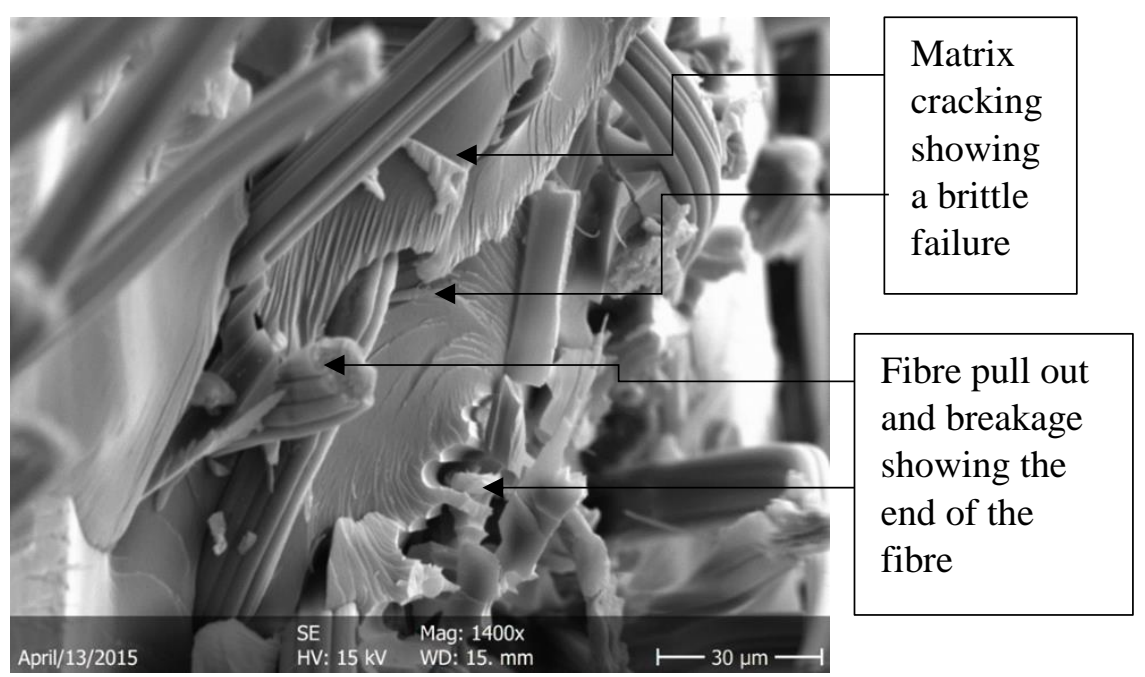

Figure 13: SEM representation image of SL1 specimen at the magnification of x1400 
Table captions:

Table 1. Composition for the sandwich laminates SL1 to SL4. UF = uniaxial fabric, $\mathrm{NWF}=$ non-woven fabric,

$\mathrm{UPR}=$ unsaturated polyester resin.

\begin{tabular}{|c|c|c|c|c|c|c|}
\hline Laminate & $\begin{array}{l}\text { UF } \\
\text { (g) }\end{array}$ & $\begin{array}{c}\text { NWF } \\
\text { (g) }\end{array}$ & $\begin{array}{c}\text { UPR } \\
\text { (g) }\end{array}$ & $\begin{array}{l}\text { UF } \\
(w t- \\
\%)\end{array}$ & $\begin{array}{c}\text { NWF } \\
\text { (wt- } \\
\%)\end{array}$ & $\begin{array}{c}\text { UF + } \\
\text { NWF } \\
(w t-\%)\end{array}$ \\
\hline Sandwich laminate (SL1) & 19 & 26 & 160 & 9.3 & 12.7 & 22.0 \\
\hline Sandwich laminate (SL2) & 38 & 18 & 150 & 18.4 & 8.7 & 27.1 \\
\hline Sandwich laminate (SL3) & 57 & 12 & 140 & 27.7 & 5.8 & 33.5 \\
\hline Sandwich laminate (SL4) & 76 & 6 & 124 & 36.9 & 2.9 & 39.8 \\
\hline
\end{tabular}


Table 2. Average impact test results for various laminates

\begin{tabular}{ccccc}
\hline Laminate types & $\begin{array}{c}\text { Maximum } \\
\text { Force } \\
(\mathbf{N})\end{array}$ & $\begin{array}{c}\text { Maximum } \\
\text { displacement } \\
(\mathbf{m m})\end{array}$ & $\begin{array}{c}\text { Maximum } \\
\text { Energy } \\
(\mathbf{J})\end{array}$ & $\begin{array}{c}\text { Energy } \\
\text { absorbed } \\
(\mathbf{J})\end{array}$ \\
\hline $\begin{array}{c}\text { Sandwich } \\
\text { laminate (SL1) }\end{array}$ & 3690.00 & 10.22 & 25.53 & 25.53 \\
\hline $\begin{array}{c}\text { Sandwich } \\
\text { laminate (SL2) }\end{array}$ & 4740.00 & 7.12 & 26.76 & 23.86 \\
\hline $\begin{array}{c}\text { Sandwich } \\
\text { laminate (SL3) }\end{array}$ & 5160.00 & 6.39 & 26.71 & 23.01 \\
\hline $\begin{array}{c}\text { Sandwich } \\
\text { laminate (SL4) }\end{array}$ & 5390.00 & 5.82 & & 26.54 \\
\hline
\end{tabular}

